\title{
A new genus and species of fairyfly, Tinkerbella nana (Hymenoptera, Mymaridae), with comments on its sister genus Kikiki, and discussion on small size limits in arthropods
}

\author{
John T. Huber ${ }^{1, \dagger}$, John S. Noyes ${ }^{2, \ddagger}$ \\ I Natural Resources Canada, clo Canadian National Collection of Insects, AAFC, K. W. Neatby building, 960 \\ Carling Avenue, Ottawa, ON, K1A OC6, Canada 2 Department of Entomology, Natural History Museum, \\ Cromwell Road, South Kensington, London, SW7 5BD, UK \\ † urn:lsid:zoobank.org:author:6BE7E99B-9297-437D-A14E-76FEF6011B10 \\ ‡ urn:lsid:zoobank.org:author:6F8A9579-39BA-42B4-89BD-ED68B8F2EA9D \\ Corresponding author: John T. Huber (john.huber@agr.gc.ca) \\ Academic editor: S. Schmidt | Received 9 January 2013 | Accepted 11 March 2013 | Published 24 April 2013 \\ urn:lsid:zoobank.org:pub:D481F356-0812-4E8A-B46D-E00F1D298444 \\ Citation: Huber JH, Noyes JS (2013) A new genus and species of fairyfly, Tinkerbella nana (Hymenoptera, Mymaridae), \\ with comments on its sister genus Kikiki, and discussion on small size limits in arthropods. Journal of Hymenoptera \\ Research 32: 17-44. doi: 10.3897/JHR.32.4663
}

\begin{abstract}
A new genus and species of fairyfly, Tinkerbella nana (Hymenoptera: Mymaridae) gen. n. and sp. n., is described from Costa Rica. It is compared with the related genus Kikiki Huber and Beardsley from the Hawaiian Islands, Costa Rica and Trinidad. A specimen of Kikiki huna Huber measured $158 \mu \mathrm{m}$ long, thus holding the record for the smallest winged insect. The smallest size possible, as measured by body length, for flying insects and wingless arthropods is discussed.
\end{abstract}

\section{Keywords}

Mymaridae, Tinkerbella, Kikiki, Dicopomorpha, Alaptus, smallest insect, smallest arthropods 


\section{Introduction}

The family Mymaridae (Hymenoptera) includes the smallest known insects. Enock (1895) observed a species of Alaptus Westwood searching for and parasitizing eggs of Psocus fasciatus Fabricius [now Loensia fasciata] (Psocoptera: Liposcelididae) and aptly gave it the English common name fairy-fly, presumably because of its small size and delicate wings with long fringes, resembling the mythical fairies. A specimen of Alaptus borinquensis Dozier was reported as being as small as $186 \mu \mathrm{m}$ (Dozier 1932). A male of Dicopomorpha echmepterygis Mockford measuring $139 \mu \mathrm{m}$ in length is the smallest insect ever recorded but males are greatly modified though losses of various body parts (Mockford 1997, Huber and Landry 2000, Huber 2009a, fig. 12.2). Megaphragma caribea Delvare (Trichogrammatidae) has been recorded at $170 \mu \mathrm{m}$ (Delvare 1993) and was, until now, the smallest winged insect known. Almost 2000 years ago, Pliny the Elder (ca. 23-79 A.D.) stated "Rerum natura nusquam magis quam in minimis tota est" loosely translated as "nature is nowhere as great as in its smallest." In the absence of any means of magnification he could not possibly have seen the intricate structure and beauty of fairyflies or other minute organisms. But his statement certainly holds true.

Here we describe a new genus of Mymaridae from Costa Rica with specimens below $250 \mu \mathrm{m}$ in length. We compare it with specimens of Kikiki, a genus described first from the Hawaiian Islands (Huber and Beardsley 2000b), then recorded from Australia (Lin et al. 2007), Argentina (Luft Albarracin et al. 2009), Costa Rica, and Trinidad and Tobago (this paper). Modified couplets for the key to Alaptus-group genera (Huber 2009b) are provided to account for the new genus but both it and Kikiki are shown to be misplaced there. Small body size in insects and other arthropods is discussed.

\section{Methods}

Specimens were collected in Costa Rica by JSN using a heavy triangular sweep net fitted with a galvanized metal screen with $4 \mathrm{~mm}$ mesh over the opening. Sweeping was done by gently dragging the net through vegetation and dumping the net contents at five minute intervals into $80 \%$ ethanol in a sturdy polythene bag to reduce damage to insects in the debris. Sweeping was done for two hours periods (barring rain) so different samples could be compared, if necessary. The samples were sorted later in a laboratory using the method described here to ensure that all the smallest Hymenoptera were found. The procedure is:

1 Stir the entire sample in $80 \%$ ethanol very gently to cause the smaller insects to float up from the bottom.

2 Using a $3 \mathrm{ml}$ teaspoon, take enough of the floating material to fill it (a slight stir allows one to gently place the teaspoon into the sample to allow material to settle on to it).

3 Add ethanol from the sample jar to a sorting dish to a depth of 2-3 mm. The sorting dish used in this case consisted of a $9 \mathrm{~cm}$ plastic Petri dish with grooves 
scored at $1 \mathrm{~cm}$ intervals on the outside and made visible by drawing black lines in India ink.

4 Examine the sorting dish contents under a binocular microscope by gently moving material across with a pair of forceps and extracting the insects desired. When finished, pour the sorted waste into a $500 \mathrm{~g}$ jar.

5 Repeat steps $1-4$.

6 After a few repetitions gently stir the jar containing the waste ethanol, allow it to settle for 10 seconds, then pour the supernatant gently into the sorting dish as in step 3 and scan for any remaining small insects.

7 When the unsorted sample has too little ethanol to stir it properly, gently stir the waste jar, allow it to settle for 10 seconds, and use the supernatant ethanol to top up the unsorted sample.

8 If there is not enough ethanol for step 8, add fresh ethanol to the waste jar, stir it slightly, and repeat step 6 .

Specimens retrieved were critical point dried and card mounted. Photographs were taken with a digital scanning camera attached to a microscope, and the resulting layers combined electronically using Syncroscopy Auto-Montage $\mathrm{e}^{\mathrm{m}}$ and, except for primary types, retouched as needed with Adobe ${ }^{\text {"' }}$ Photoshop. Micrographs were taken with a Philips environmental scanning electron microscope (ESEM) from uncoated specimens on their cards. A few specimens were slide mounted, either with prior clearing in $10 \% \mathrm{KOH}$ or without clearing.

Morphological terms are according to Gibson (1997) and Huber (2012). Abbreviations used are: $f_{x}=$ funicle segment $x ; g_{x}=$ gastral tergum $x$. Measurements in micrometres $(\mu \mathrm{m})$ were taken from card mounted specimens at 200x using an ocular micrometer on a Zeiss microscope, and the two smallest specimens of Kikiki were also measured with the ESEM measurement tool. Slide-mounted specimens were measured at $200 \times$ or $400 \times$ magnification using a filar micrometer on a compound microscope. Specimens are deposited in the following institutions:

BMNH Department of Entomology, The Natural History Museum, London, UK.

CNC Canadian National Collection of Insects, AAFC, Ottawa, ON, Canada

INBio Instituto National de Biodiversidad, San José, Costa Rica.

UCRC University of California, Riverside, CA, USA.

\section{Taxonomy}

Tinkerbella Huber \& Noyes, gen. n. urn:Isid:zoobank.org:act:E3F95FC3-C247-41D3-90F9-47C7724EA7E3 http://species-id.net/wiki/Tinkerbella

Type species: Tinkerbella nana Huber and Noyes. 
Derivation of genus name. After the fairy Tinker Bell in the 1904 play "Peter Pan" by J.M. Barrie. Gender: feminine.

Diagnosis. Tinkerbella is defined by the following combination of features: body length at most about $250 \mu \mathrm{m}$; female antenna with funicle 5-segmented and clava entire (Figs 1, 3, 5, 13), compound eye with about 50 ommatidia (Figs 11, 13), and tarsi 4-segmented (Fig. 22).

Kikiki is the most closely related genus to Tinkerbella. It is distinguished from Tinkerbella by the following combination of features: female with funicle 4-segmented and clava 2-segmented (Figs 24, 37, 38), compound eye with about 20-25 ommatidia (Figs 24, 38, 39, 40), and tarsi 3-segmented (Fig. 47, 48).

Description. Female. Body minute, at most about $250 \mu \mathrm{m}$ long. Head in dorsal view (Fig. 12) about 1.6x as wide as long, in lateral view (Fig. 11) about $1.6 \times$ as high as long, and in anterior view (Figs 5,9) about $1.3 \times$ as wide as high. Face slightly longer than wide and ventrally separated from clypeus by curved epistomal sulcus. Toruli about their own diameter from transverse trabecula. Clypeus apparently extending entire width of mouth opening, with anterior tentorial pits visible, slit-like (Fig. 10). Mandible with 4 teeth, the lower one more distinct than the upper three (Fig. 10). Eye with about 50 facets, in lateral view about $1.4 \times$ as high as long and not extending to back of head dorsally. Malar distance about $0.4 \times$ eye height, with straight malar sulcus. Vertex at about right angle to face above toruli, with supraorbital trabecula divided medially into two parts. Ocelli in normal triangle with POL: LOL: OOL about 1.1: 0.5: 0.5, enclosed by conspicuous rectangular stemmaticum and with sulci extending laterally to endpoints of posterior section of supraorbital trabecula (Fig. 12); occiput divided by transverse sulcus just dorsal to foramen medially and ventral to eyes laterally (Fig. 17). Antenna. Scape about $3.9 \times$ as long as wide, with faint longitudinal reticulations on outer surface and distinct transverse ridges on inner surface (Figs 5,13$)$. Pedicel about $0.2 \times$ as long as scape. Funicle 5-segmented. clava entire (a faint, partial division visible, however) (Figs 5, 13). Mesosoma. About $1.34 \times$ as long as high and about $1.3 \times$ as long as wide. Pronotum thin, in dorsal view scarcely visible (Fig. 7), in lateral view with large lateral panel extending posteriorly to level of wing base (Fig. 11). Mesoscutum (Figs 16, 17) slightly longer than scutellum, with deep notauli. Anterior scutellum and axilla completely separated by deep straight transverse sulcus from slightly longer, longitudinally divided frenum. Second phragma projecting to apex of propodeum. Metanotum with dorsellum distinct, about $0.5 \times$ as long as frenum, apparently divided by a median longitudinal groove (Figs $16,17)$, and much wider than very narrow lateral panel of metanotum (Figs 16, 17). Mesopleuron (Fig. 17) divided by fairly straight, faint transepimeral sulcus into narrower mesepisternum and wider mesepimeron. Metapleuron triangular. Propodeum in dorsal view (Fig. 16) with anterodorsal area mostly smooth, posterodorsal area with minute rounded spicules medially, with propodeal seta about midway between spiracle and posterior margin of propodeum; in lateral view (Fig. 18) strongly sloping. Propodeal spiracle circular, smaller than pronotal spiracle and distinctly separated from anterior margin of propodeum. Wings. Fore wing (Figs 6, 8, 20) narrow, almost parallel sided, with posterior margin distinctly concave beyond pronounced lobe (Fig. 21) at level of parastigma; 


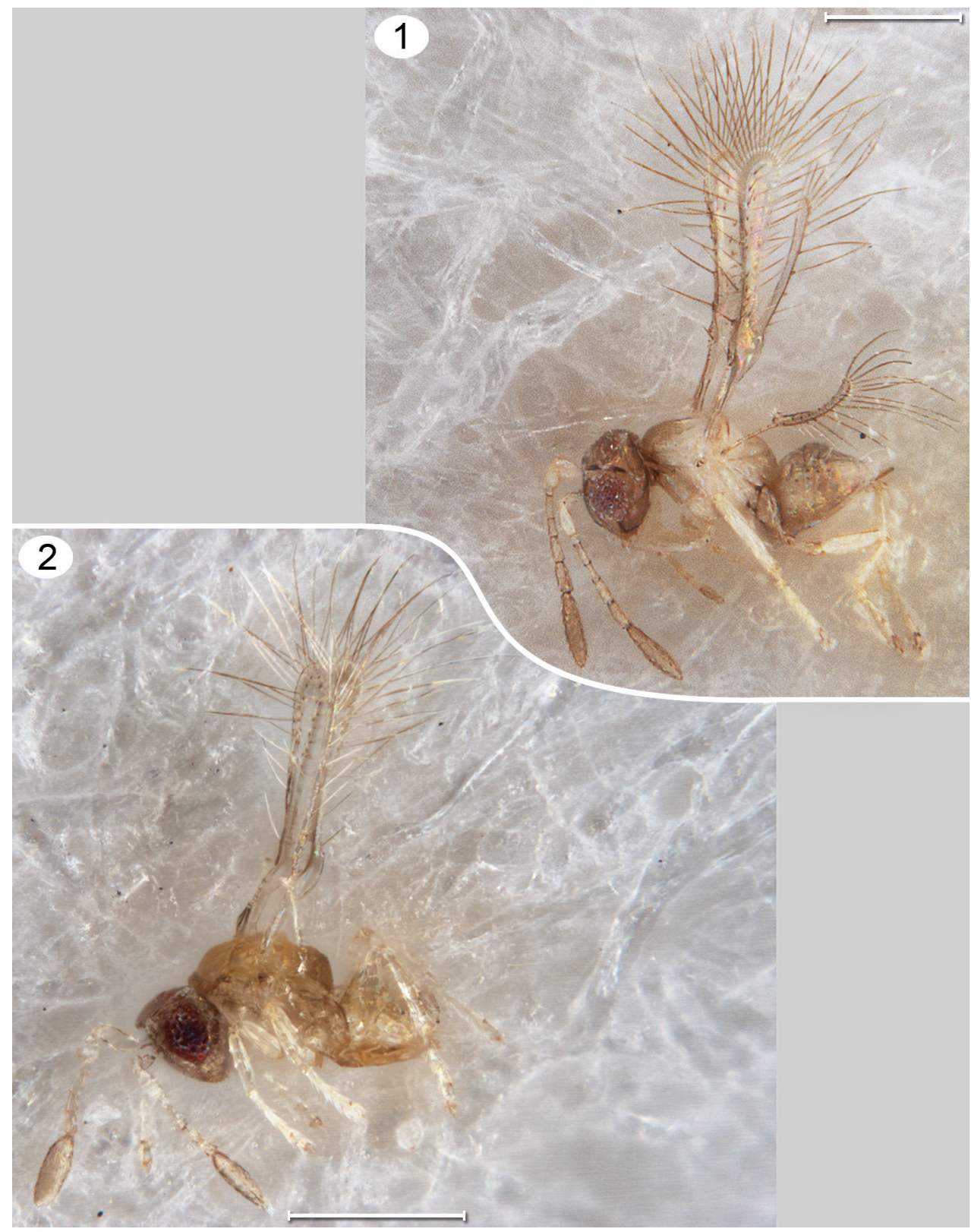

Figures I, 2. Habitus, lateral. I Tinkerbella nana female 2 Kikiki huna, female. Scale line $=100 \mu \mathrm{m}$.

wing surface bare except for fewer than about 10 scattered microtrichia on dorsal and ventral surfaces; fringe setae much longer than wing width. Venation extending almost $0.7 \times$ fore wing length; submarginal vein about $1.6 \times$ parastigma length, and parastigma about $0.5 \times$ marginal + stigmal vein lengths (their relative proportions about 24/15/29); hypochaeta close to proximal macrochaeta (Fig. 21); parastigma with distal macrochaeta 
about $3 \times$ as long as proximal macrochaeta (Fig. 21). Hind wing (Figs 6, 8) curved, with anterior margin concave, paralleling convex posterior margin, apex bluntly rounded, with long fringe setae at apex and along posterior margin to just beyond level of relatively large hamuli; wing surface bare except for row of fewer than about 8 microtrichia along anterior margin except toward hamuli where they are located more posteriorly. Legs. Tarsi 4-segmented, tarsomere 1 slightly shorter than remaining tarsomeres, and tarsomere 4 distinct, as long as tarsomere 3 (Fig. 22). Metasoma. Slightly shorter than mesosoma (critical point dried specimens) (Fig. 7); petiole very short (scarcely visible), about $4.3 \times$ as wide as long, but clearly narrower than $\mathrm{gt}_{1}$; gaster in dorsal view distinctly narrower anteriorly than medially (Fig. 7) with gt ${ }_{6}$ the longest tergite and apparently without a spiracle. Ovipositor (Figs 7,18) as long as gaster, slightly exserted beyond gastral apex. Cerci with 3 long setae extending just beyond ovipositor apex (Fig. 19).

Male. Antenna 11-segmented (Fig. 14), with 2 mps each, except $\mathrm{fl}_{3}$ and $\mathrm{fl}_{5}$ much shorter and without mps (Fig. 15), the mps decreasing in width on each segment, from almost circular on $\mathrm{fl}_{1}$ to linear on $\mathrm{fl}_{11}$.

\section{Tinkerbella nana Huber \& Noyes, sp. n.} urn:lsid:zoobank.org:act:EFCB279C-935F-4098-873F-4B7C5C935E8F http://species-id.net/wiki/Tinkerbella_nana

Figs 1, 3-22

Holotype $q$ (INBio) on slide labelled, 1. "COSTA RICA: Heredia, La Selva, 75m, $10^{\circ} 26^{\prime} \mathrm{N}, 84^{\circ} 01^{\prime} \mathrm{W}, 27-28 . i i .2003$, J.S. Noyes, sweeping, cleared in clove oil, mounted in Canada balsam". 2. "Tinkerbella nana Huber and Noyes + dorsal Holotype".

Paratypes. $7 q$ and $2{ }^{\circ}$. COSTA RICA: Alajuela. Reserva Rincón Forestal, Estación Caribe, $400 \mathrm{~m}, 10^{\circ} 53^{\prime} \mathrm{N}, 85^{\circ} 18^{\prime} \mathrm{W}, 400 \mathrm{~m}, 19-22 . i i .2003$, J.S. Noyes $\left(19\right.$, $10^{\Uparrow}$, CNC); Arenal National Park, sendero Pilón $10^{\circ} 27^{\prime} \mathrm{N}, 84^{\circ} 43^{\prime} \mathrm{W}, 600 \mathrm{~m}, 26 . i i .2003$, J.S. Noyes ( 1 ,, $\mathrm{CNC})$. Heredia. Same data as holotype (5ㅇ, $\left.10^{\Uparrow}, \mathrm{CNC}, \mathrm{BMNH}, \mathrm{InBio}\right)$.

Derivation of species name. After the dog Nana in Peter Pan and coincidentally from nanos, the Greek word for dwarf. Treated as a (feminized) noun in apposition.

Description. Female. Body length $225-250 \mu \mathrm{m}(\mathrm{n}=6)$. Colour. Very pale, the scape, pedicel, pronotum laterally, gaster laterally, and legs except apical tarsomere sometimes lighter, almost white; head, mandibles, mesoscutum, anterior scutellum and propodeum with a pale yellow or pale brown tinge, occasionally head and mesosoma, especially mesoscutum, more uniformly and extensively brown; trabeculae and a minute spot next to fore wing base dark brown; eyes and ocelli distinctly reddish (Fig. 3). Fore wing with brown tinge behind most of venation except its apex (Fig. 6). Hind wing fairly uniformly light brown from just before hamuli to slightly lighter apex. Head. 65-99 wide, with transverse reticulate sculpture on face (Fig. 9), vertex (Fig. 12), and occiput (Fig. 12). Antenna. Flagellum (Figs 5, 13) with $1 \mathrm{mps}$ on $\mathrm{fl}_{4}$, $1 \mathrm{mps}$ on $\mathrm{fl}_{5}$, and $4 \mathrm{mps}$ on clava. $\mathrm{Fl}_{1}$-clava length/width ( $\mathrm{n}=2$-width or 4 -length): scape, 25-30/13-14, pedicel 19-27/17-18, $\mathrm{fl}_{1} 8-10 / 7-8, \mathrm{fl}_{2} 12-21 / 6-7, \mathrm{f}_{3} 11-16 / 7-$ 


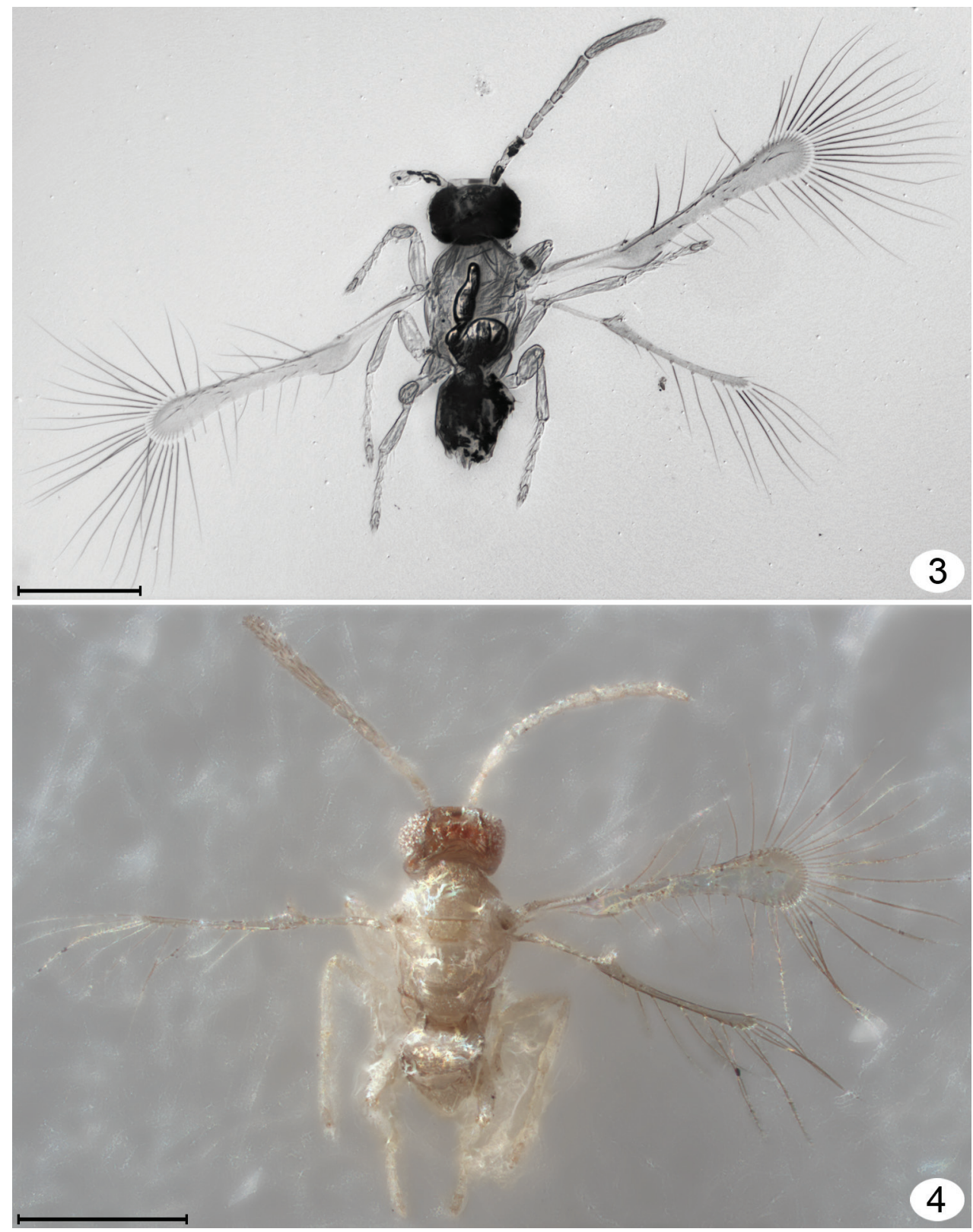

Figures 3, 4. Tinkerbella nana female. 3 holotype, uncleared on slide $\mathbf{4}$ paratype, critical point dried on card. Scale line $=100 \mu \mathrm{m}$.

8, $\mathrm{fl}_{4}$ 8-24/9, $\mathrm{fl}_{5}$ 23-31/10-11, clava 59-65/15-17. Mesosoma. Mesoscutum (Figs 7, $16,17)$ with slightly longitudinal, reticulate sculpture and raised meshes. Scutellum smooth anteriorly, frenum slightly wrinkled. Dorsellum smooth to slightly wrinkled. Wings. Fore wing with a few scattered microtrichae behind venation from proximal 


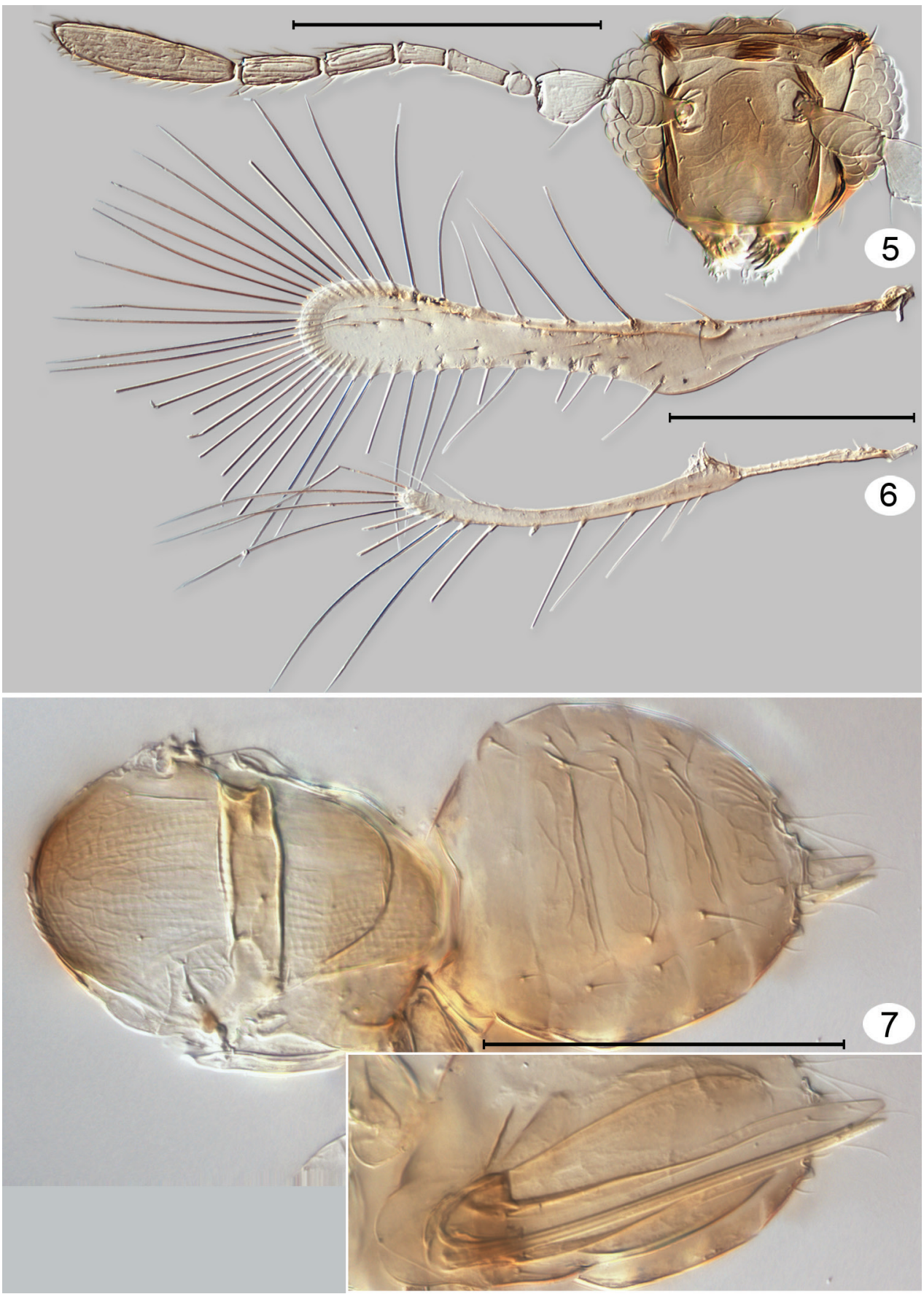

Figures 5-7. Tinkerbella nana female paratype, cleared on slide. 5 head + right antenna, anterior $\mathbf{6}$ wings 7 mesosoma + metasoma dorsal, and ovipositor ventral (inset). Scale line $=100 \mu \mathrm{m}$. 


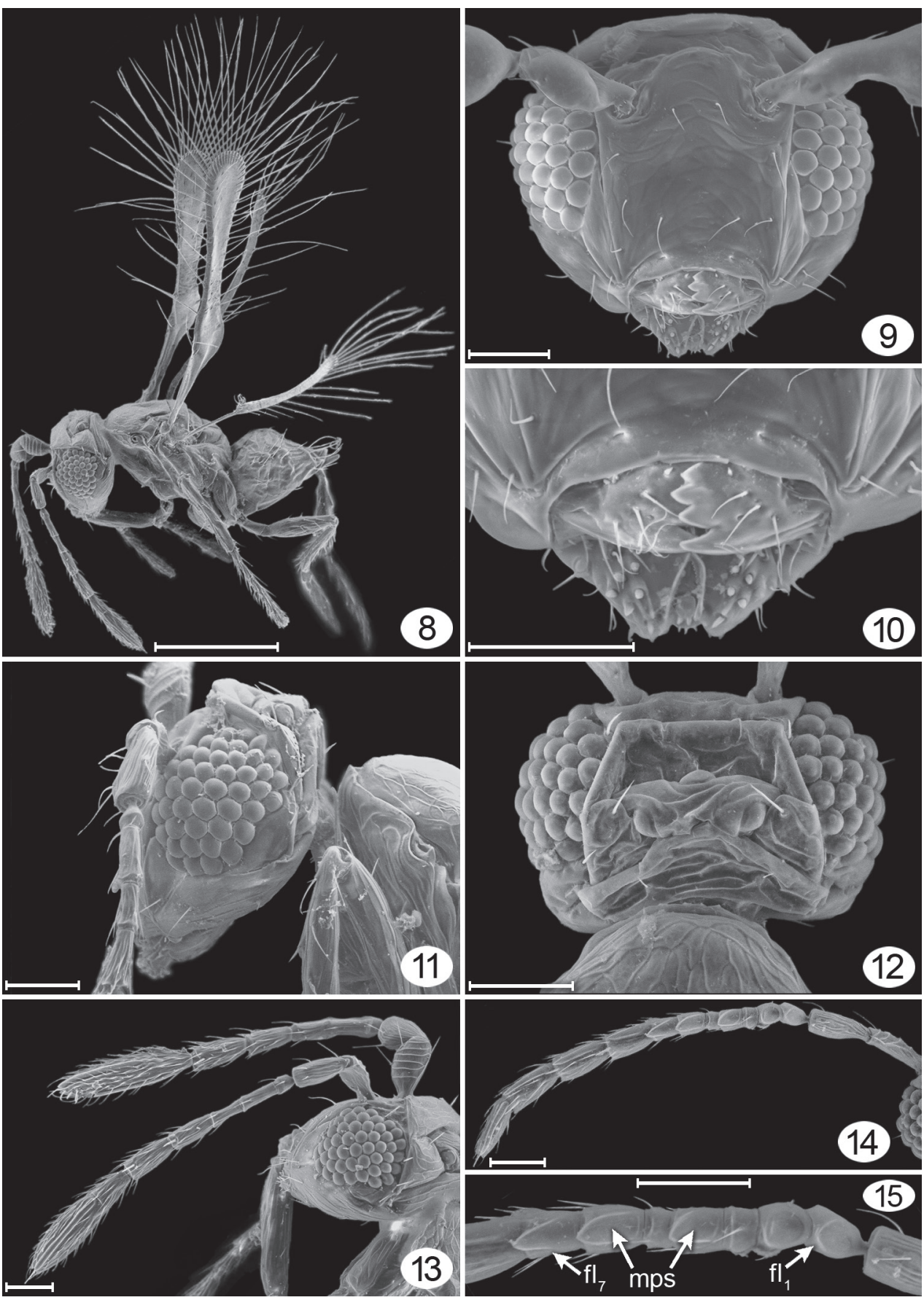

Figures 8-15. Tinkerbella nana paratype female (except 14, 15), micrographs. 8 habitus, lateral 9 head, anterior $\mathbf{I} \mathbf{0}$ mouthparts, anterior $\mathbf{I} \mathbf{I}$ head + pronotum, lateral $\mathbf{I} \mathbf{2}$ head, dorsal $\mathbf{I} \mathbf{3}$ head + antennae, lateral I4 male antenna, dorsal I 5 male antenna, pedicel $-\mathrm{fl}_{8}$, dorsal. Scale line $=20 \mu \mathrm{m}$, except Fig. $8=100 \mu \mathrm{m}$. 
macrochaeta on, and 3 or 4 just beyond venation (Fig. 6). Fore wing length 195-240 $(\mathrm{n}=5$, card mounts at 200x), width 30-50, longest marginal setae 100-155; hind wing length 145-200, width 5-10, longest marginal setae 105-130. Metasoma. Petiole 34 wide, 7 long $(\mathrm{n}=1)$. Gaster with segments somewhat wrinkled and sometimes transversely creased posteriorly (Figs 7,18 ); $\mathrm{gt}_{2}-\mathrm{gt}_{6}$ each with a few fairly long, suberect setae dorsally and laterally.

Male. Body length 210-230 $\mu \mathrm{m}(\mathrm{n}=2)$. Colour light brown (Fig. 4). $\mathrm{Fl}_{3}$ and $\mathrm{fl}_{5}$ the shortest segments, less than half length of the segment following and without mps (Fig. 15).

Hosts and habitat. Unknown. The specimens from Alajuela were collected by sweeping in fairly young secondary forest (20 years old maximum) mixed with a small amount (ca. 1 ha) of primary forest.

Distribution. Costa Rica.

\section{Kikiki Huber \& Beardsley}

http://species-id.net/wiki/Kikiki

Kikiki: Huber and Beardsley 2000b: 66 (original description); Huber 2009b: 235 (key); Luft Albarracin et al. 2009: 12 (key); Lin et al. 2007: 16 (key [male]), 37 (diagnosis).

Remarks. Specimens of Kikiki from Costa Rica were collected and examined since the original generic description based on eight specimens from the Hawaiian Islands (Huber and Beardsley 2000b). Additional features not seen clearly or at all on the slidemounted type series can therefore be described. Based on the images and better slide mounts, several corrections to the original description are made: the axilla is distinctly advanced (Figs 26, 44), the lateral lobe of the mesoscutum has 1 seta (Fig. 26), and the second phragma (mesophragma) does not project into the gaster. A cleared and slide mounted Costa Rica specimen has 3 mps on the apical claval segment but none elsewhere, and JTH checked one paratype (CNC) and found that it also lacks mps on $\mathrm{fl}_{4}$ and on the basal segment of the clava-the apparent mps (Huber and Beardsley 2000b, fig. 3) are actually not mps but an artifact of lighting.

Description. Female. Head. Face about $1.7 \times$ as high as wide, slightly depressed medially (Fig. 24), separated ventrally from oral cavity by distinct epistomal suture. Clypeus transverse, in same plane as face, narrowly oval and extending entire width of oral cavity, with anterior tentorial pits visible sublaterally (Fig. 37). Mandible with lower tooth separated from remaining teeth by deeper notch than notches separating the teeth above it. Vertex (Figs 30, 40) laterally with well defined supraorbital trabecula divided medially; ocelli enclosed by a distinct, rectangular stemmaticum, the vertex thus divided into anterior (smooth) and posterior (faintly sculptured) areas by a transverse groove extending between eyes from just anterior to each supraorbital trabecula and along anterior margin of slightly triangular mid ocellus; lateral ocelli almost vertical, facing away from each 

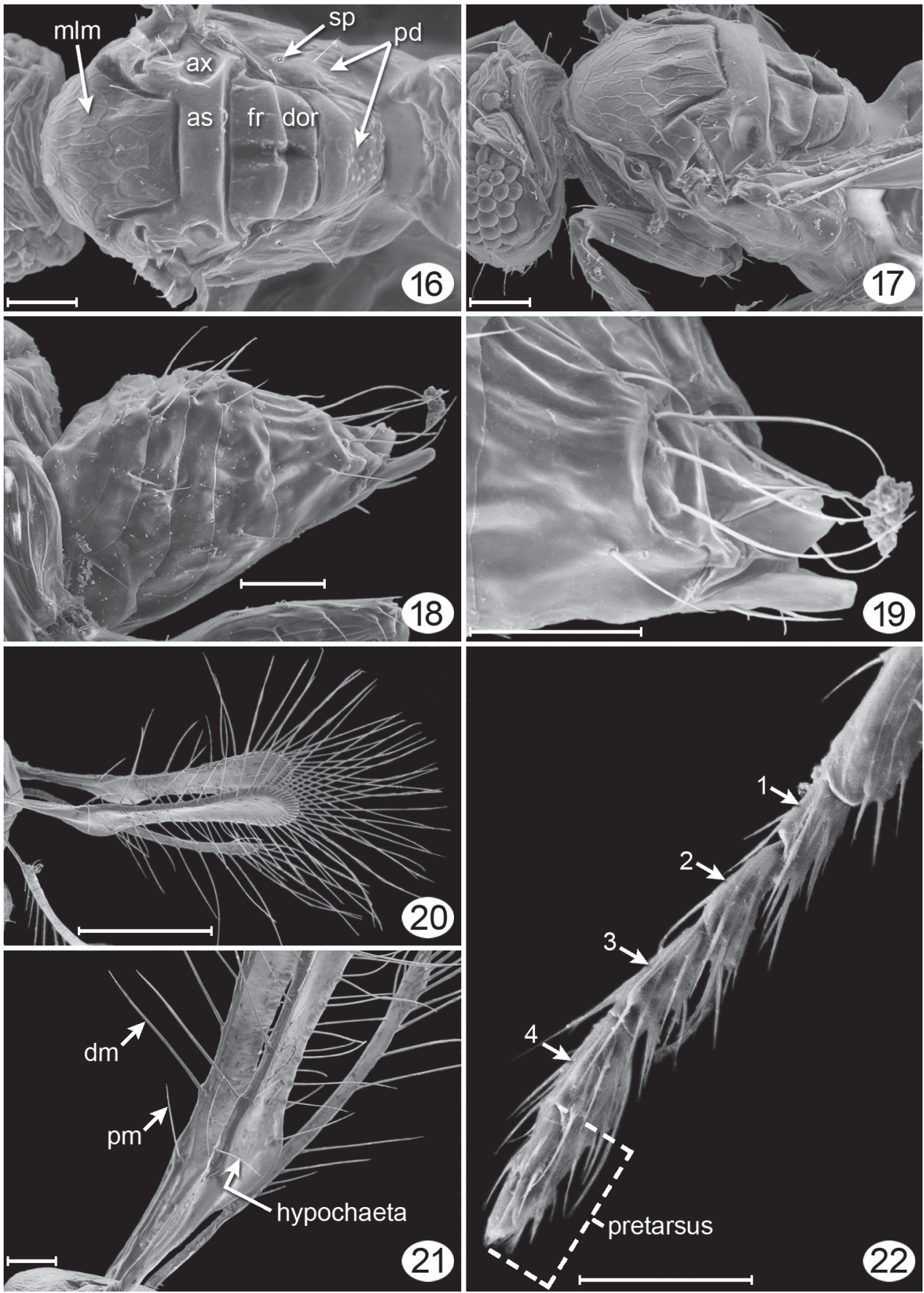

Figures 16-22. Tinkerbella nana female paratype, micrographs. 16 mesosoma, dorsal $\mathbf{1 7}$ mesosoma + back of head, dorsolateral 18 metasoma, lateral 19 apex of gaster, dorsolateral $\mathbf{2 0}$ wings (left wing ventral surface, right wing dorsal surface) $\mathbf{2} \mathbf{I}$ wing, basal half $\mathbf{2 2}$ left mesotarsus. See appendix for abbreviations. Scale line $=20 \mu \mathrm{m}$, except Fig. $20=100 \mu \mathrm{m}$. 


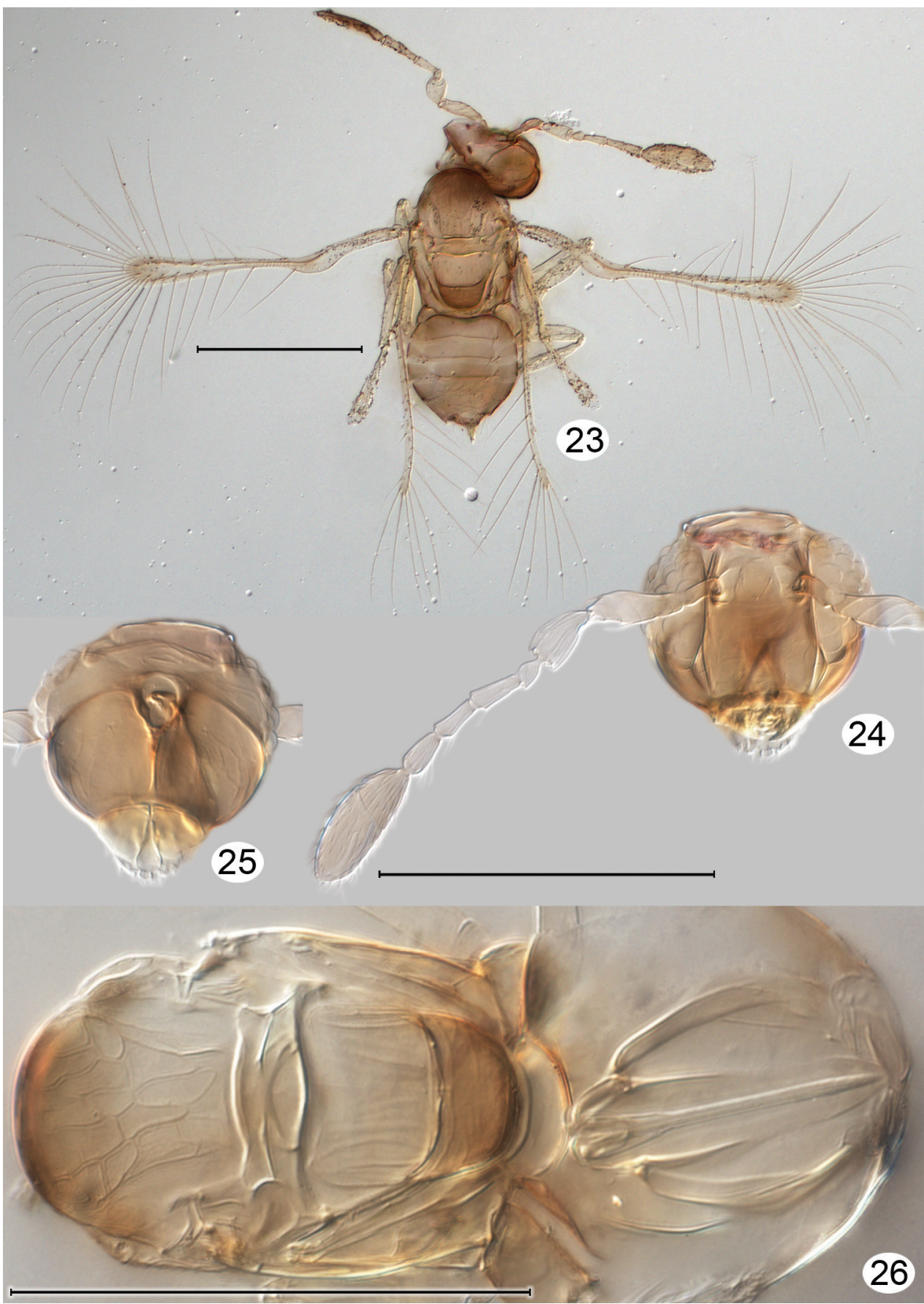

Figures 23-26. Kikiki huna female, on slide (cleared, except Fig. 23). 23 habitus, dorsal $\mathbf{2 4}$ head + right antenna, anterior $\mathbf{2 5}$ head, posterior $\mathbf{2 6}$ mesosoma, dorsal + metasoma, dorsal but focus at lower plane to show ovipositor. Scale line $=100 \mu \mathrm{m}$. 


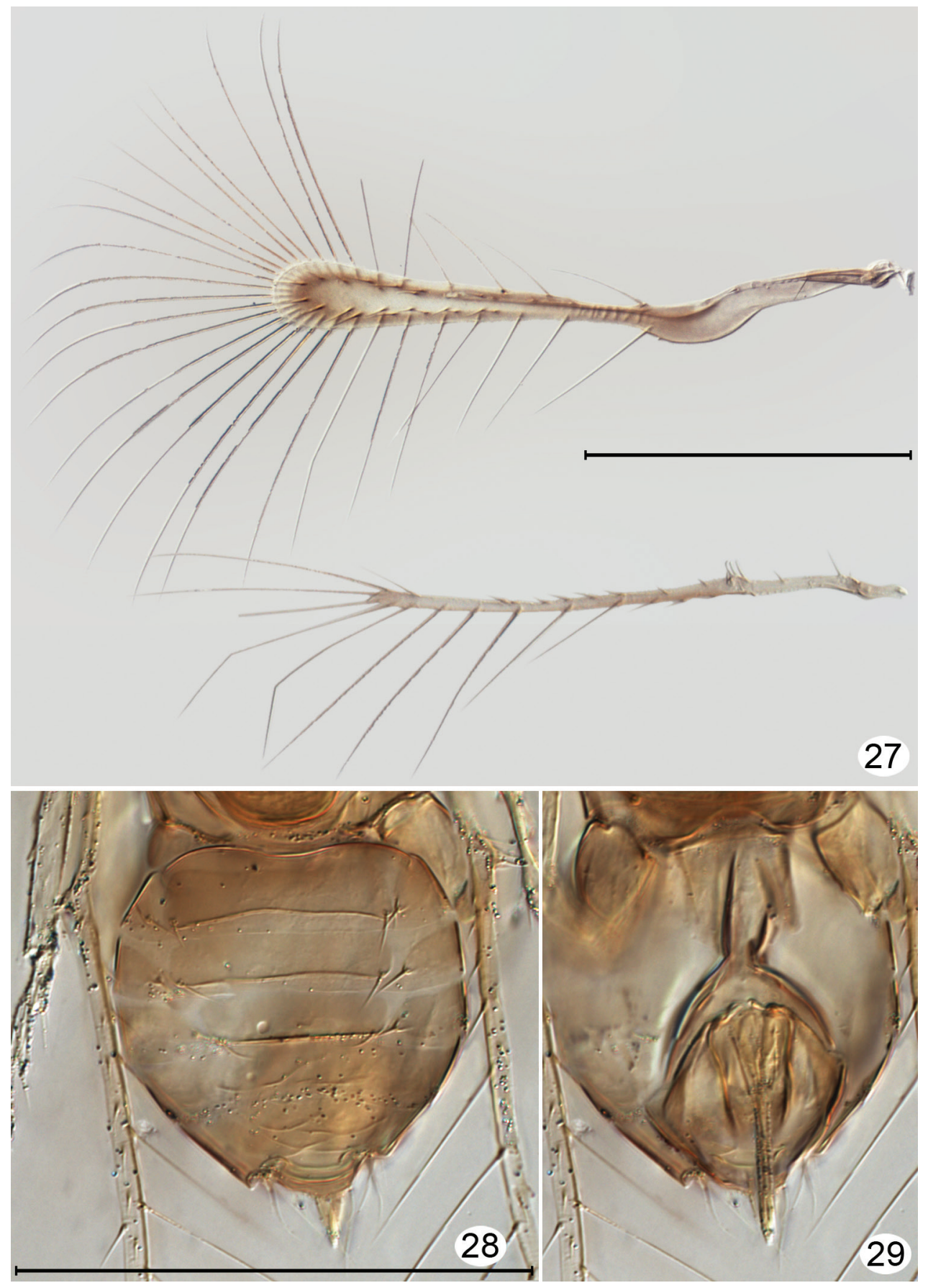

Figures 27-29. Kikiki huna female, cleared on slide. $\mathbf{2 7}$ wings $\mathbf{2 8}$ metasoma, dorsal surface $\mathbf{2 9}$ metasoma, ventral surface (seen dorsally through cleared metasoma). Scale line $=100 \mu \mathrm{m}$. 
other. Occiput separated from vertex by slightly curved groove extending between posterior apex of each supraorbital trabecula and almost touching lateral ocelli (Figs 40, 41), and occiput divided into dorsal and ventral areas by curved groove extending between lower margin of eyes and above foramen (Figs 25, 42). Head, except vertex anteriorly, with faint, reticulate sculpture. Mesosoma. Pronotum with a slightly crenulated dorsal margin (Figs 40, 42). Mesoscutum (Figs 26, 42, 44) with notauli narrow near anterior apex, distinctly widening (narrowly triangular) posteriorly to the medially deep and wide transscutal articulation. Scutellum with axilla strongly advanced anteriorly into lateral lobe of mesoscutum. Frenum apparently divided mediolongitudinally by a wide depression (Figs 44, 45). Mesosoma except anterior scutellum with faint, reticulate sculpture. Legs. Fore leg with bifurcate strigil and calcar with 4 rounded teeth, separated from one another by almost their own diameter (Fig. 34-male). Metasoma. Petiole (Fig. 26) extremely short and distinctly narrower that gt ${ }_{1}$. Terga each with a median transverse fold extending across tergum medially or nearer posterior margin (Figs 28, 45, 46).

Male. Body $235 \mu \mathrm{m}$ from transverse trabecula to gastral apex (Fig. 30). Antenna with 9-segmented funicle (Fig. 33; Lin et al. 2007, fig. 154), with $\mathrm{fl}_{1}$ the shortest and $\mathrm{fl}_{9}$ the longest, and each segment with 2 mps. Eye large (Fig. 30) with many ommatidia (about 40?); ocular apodeme long, narrow and parallel side for most of its length, slightly widened apically (Fig. 32). Mandibles with 4 teeth. Occiput with strongly curved groove (Fig. 31) different in shape from female, apparently extending from mouthparts, along posterior eye margin, and inwards to lateral margins of foramen. Petiole short but distinct, about $3.7 \times$ as wide as long. Spiracle absent. Cerci with 4 setae. Genitalia encapsulated; aedeagus almost as long as aedeagal apodemes (Fig. 35).

The male is described from a single slide-mounted specimen from Australia. No males have yet been collected in the New World. Whether the larger body and eyes of the Australian specimen are sex differences or indicative of a species different from $K$. huna cannot be determined until females are obtained from the same locality in Western Australia and compared with the Hawaiian and Neotropical specimens.

\section{Kikiki huna Huber \& Beardsley}

http://species-id.net/wiki/Kikiki_huna

Figs 2, 23-48

Description. Female. Body length (critical point dried specimens) 158-190 $\mu \mathrm{m}$ $(\mathrm{n}=10)$. Antenna. Funicle segments and basal claval segment without mps, apical claval segment with $3 \mathrm{mps}$ (Figs 24, 43). Antennal length/width measurements ( $\mathrm{n}=4$, Costa Rica specimens): scape, 36-47/10-11, pedicel 19-25/12-13, $\mathrm{fl}_{1} 8-9 / 5-6, \mathrm{fl}_{2}$ $16-18 / 6, f_{3} 14-17 / 6-7, f_{4} 12-18 / 7-8$, clava 46-54/15. Wings. Fore wing (Fig. 27) length 182-226, width 20-24, length/width 9.10-9.24, longest marginal setae 102123 ( $\mathrm{n}=3$, slide mounts), hind wing (Figs 23, 27) length 162-198, width 4-5, longest marginal setae $96(n=1-3)$.

Male. Unknown for Neotropical region. 

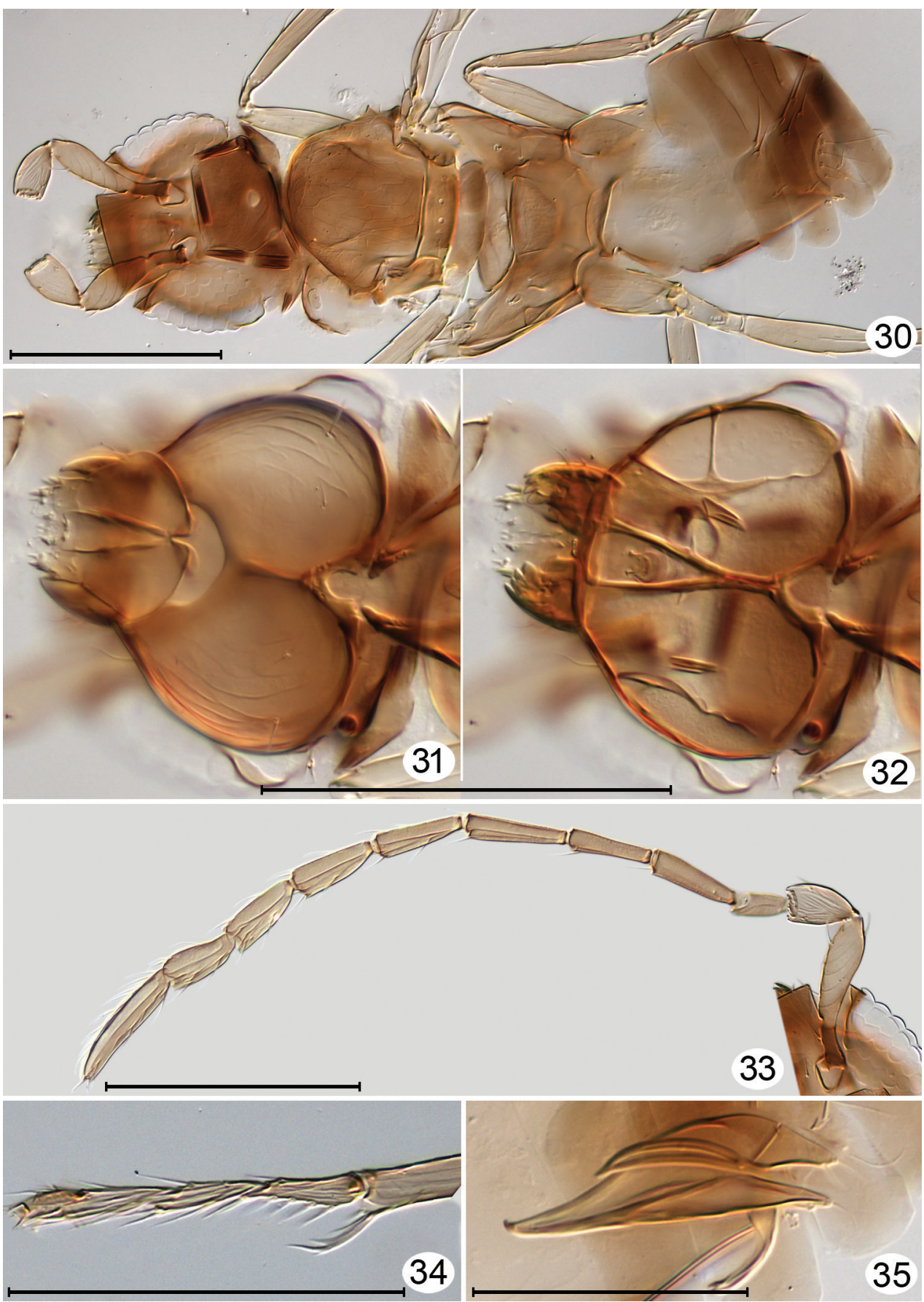

Figures 30-35. Kikiki sp. male, cleared on slide. $\mathbf{3 0}$ head anterodorsal + mesosoma and metasoma, dorsal $\mathbf{3 1}$ head, posterior $\mathbf{3 2}$ head from anterior, focused at different plane to show internal skeleton and mandibles $\mathbf{3 3}$ antenna $\mathbf{3 4}$ protarsus $\mathbf{3 5}$ genitalia, dorsolateral. Scale line $=100 \mu \mathrm{m}$, except Figures 34 and $35=50 \mu \mathrm{m}$. 

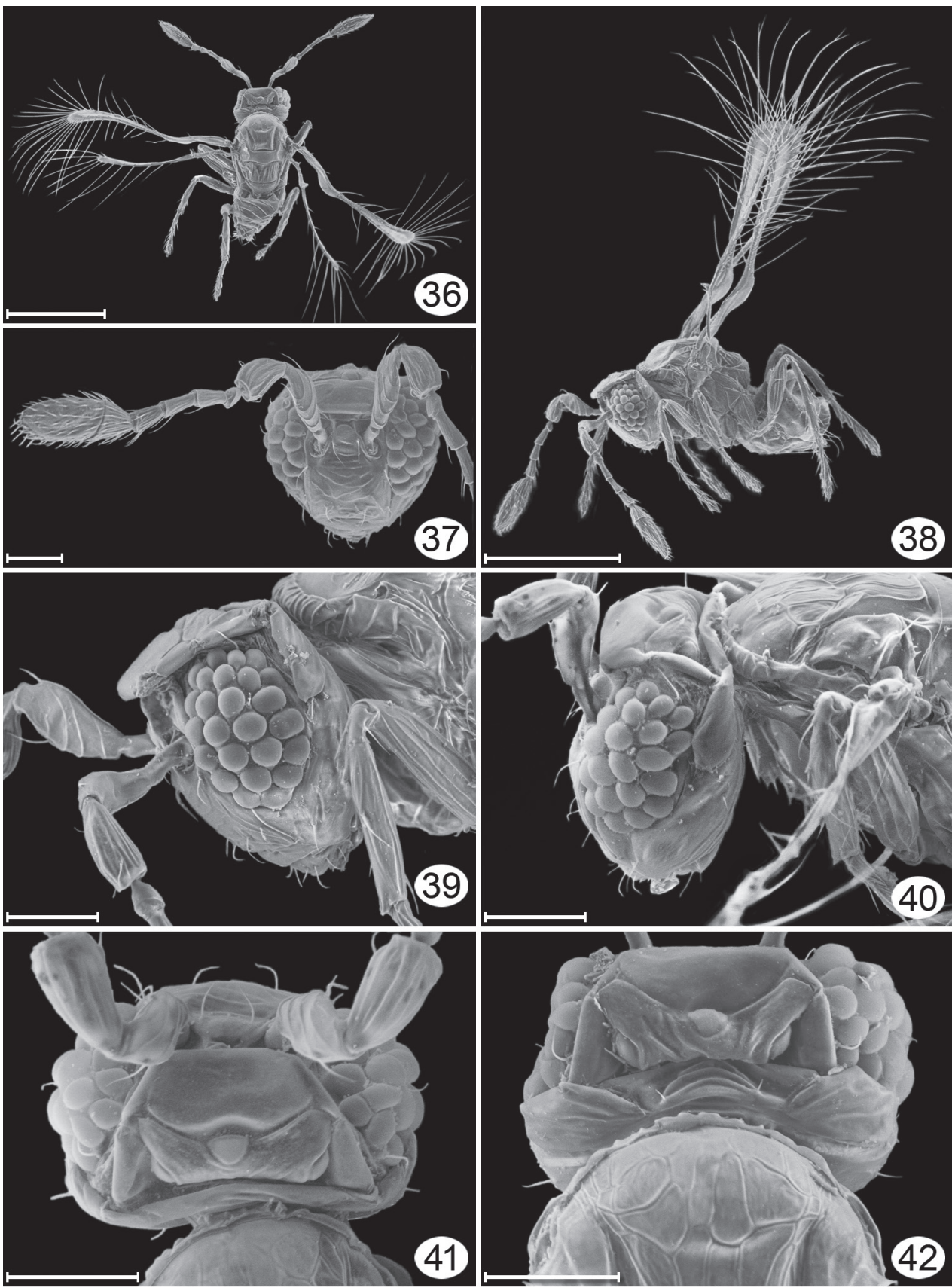

Figures 36-42. Kikiki huna female, micrographs. 36 habitus, dorsal 37, head + antennae, anterior $\mathbf{3 8}$ habitus, lateral $\mathbf{3 9}$ head, lateral $\mathbf{4 0}$ head + anterior mesosoma, dorsolateral $\mathbf{4 I}$ head + base of antenna, dorsal $\mathbf{4 2}$ head, posterodorsal + anterior mesosoma, dorsal. Scale line $=20 \mu \mathrm{m}$, except 36, $38=100 \mu \mathrm{m}$. 


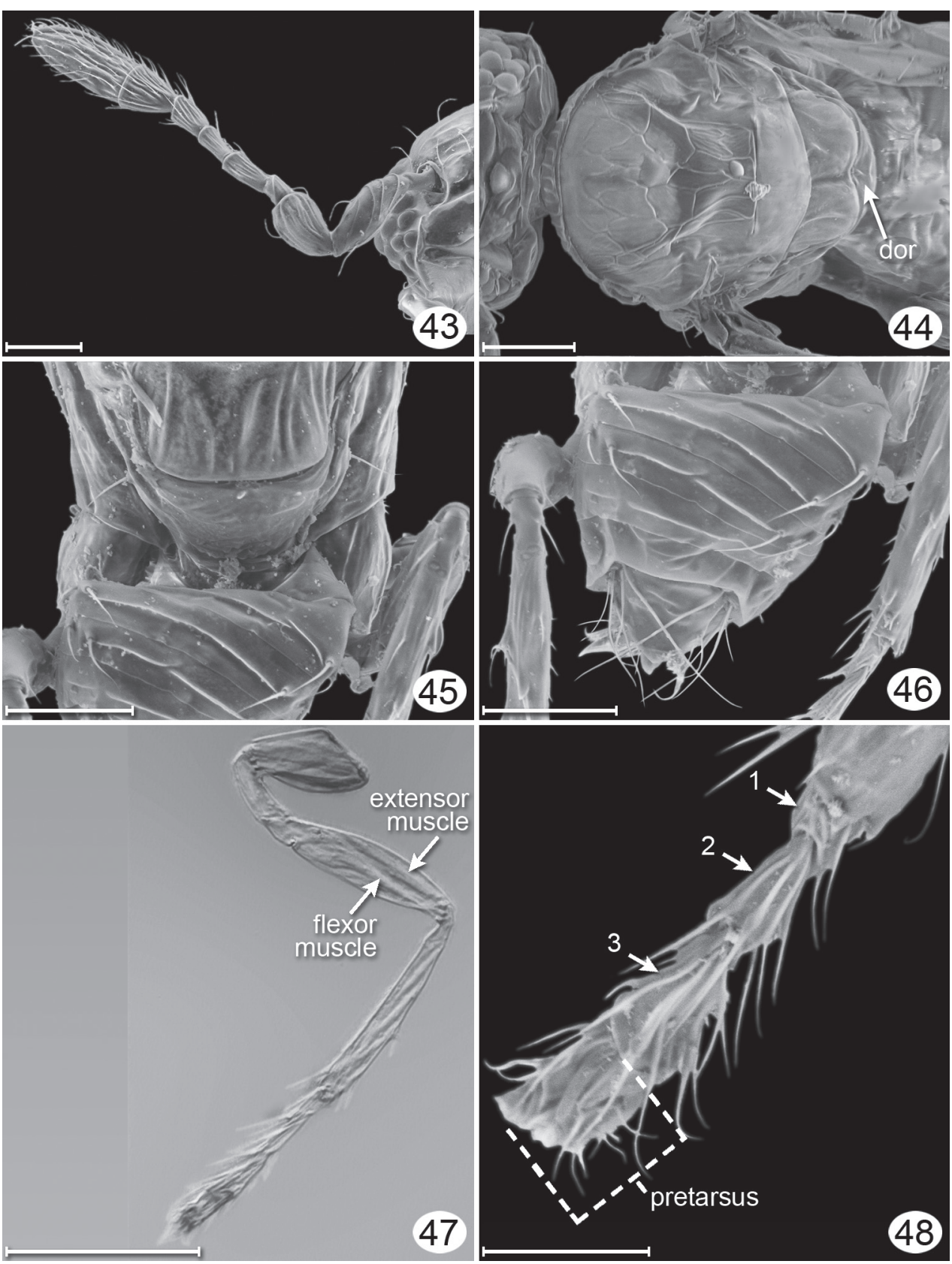

Figures 43-48. Kikiki huna, female, micrographs except Fig. 47.43 antenna, lateral 44 mesosoma, dorsal 45 frenum - anterior half of metasoma, dorsal 46 metasoma, dorsal 47 hind leg, uncleared lateral, showing muscles; 48, right metatarsus, dorsal. Scale line $=20 \mu \mathrm{m}$, except Fig. $47=50 \mu \mathrm{m}$ and $\mathbf{4 8}=10 \mu \mathrm{m}$. 
Material examined. 20 . COSTA RICA. Heredia. La Selva Biological Station, $10^{\circ} 26^{\prime} \mathrm{N}, 84^{\circ} 01^{\prime} \mathrm{W}, 75 \mathrm{~m}, 27-28.1 i .2003$, J.S. Noyes (1, CNC). Puntarenas. La Gamba Biological Station, $8^{\circ} 42^{\prime} \mathrm{N}, 83^{\circ} 12^{\prime} \mathrm{W}, 150 \mathrm{~m}, 13-14 . i i .2006$, J.S. Noyes (1q, BMNH); Reserva Absoluta Cabo Blanco, 9³5'N, 85³6'W, 30m, 16-17.ii.2009, J.S. Noyes, sweeping (9, CNC, INBio, UCRC); Reserva Privada Karen Morgensen, 952'N, 8503'W, 305m, 23-24.ii.2007, J.S. Noyes, sweeping (6q, BMNH). HAWAIIAN ISLANDS. Molokai I.: Mapulehu ( $1 q$ paratype, CNC). TRINIDAD \& TOBAGO. Trinidad. Curepe, Santa Margarita Circular Road, 8.xii.1974-2.ii.1975, F.D. Bennett (2 9 , CNC).

Discussion. We cannot find any morphological differences suggesting that the specimens from Costa Rica and Trinidad are different from the Hawaiian specimens. The number and distribution of mps on the antennal segments as reported by Huber and Beardsley (2000b) are incorrect, as mentioned above. Both the Hawaiian and the Neotropical American specimens have the same mps distribution. The body length of the former averages slightly larger, from 190-ca $330 \mu \mathrm{m}$ long (Huber and Beardsley 2000 b) but this is insufficient evidence for species separation.

At the genus level, and even the species level, the Hawaiian fauna at low elevation appears to be almost entirely represented by exotic species (Huber and Beardsley 2000a, Beardsley and Huber 2000, Triapitsyn and Beardsley 2000), except for one genus (Polynema) that has numerous, native species at higher elevations. Although $K$. huna appeared to be endemic (Huber and Beardsley 2000b), this is simply because specimens of the genus had not yet been collected elsewhere-not surprising given their minute size. Specimens have since been found in Argentina (Luft Albarracin et al. 2009), Australia (Lin et al. 2007) and Costa Rica (this paper) indicating that the genus is widespread. Given its mostly low elevation range in the Hawaiian Islands it was almost certainly accidentally introduced from elsewhere. We therefore treat all the specimens as the same species and suggest $K$. huna in the Hawaiian Islands came originally from Central America.

Tinkerbella would key to Kikiki in Huber (2009b) because at the time he thought that the genus included species with a variable number of tarsomeres (3 or 4) and, in females, funicle segments ( 4 or 5 ) and clava segments (1 or 2). Because Tinkerbella is distinct on other features as well it is described here as a new genus. Huber (2009b) and Lin et al. (2007) included Kikiki in the Alaptus group of genera, mainly because of its minute size. If the key in Huber (2009b) is used, couplet 1 should be deleted and replaced with the following two couplets at the beginning of the key to separate Tinkerbella and Kikiki from the remaining Alaptus-group genera, and to distinguish them from each other.

1 Venation long, clearly more than half wing length; tarsi 3- or 4-segmented.... 1a

- Venation short, clearly less than half wing length; tarsi 5-segmented

1a Clava 2-segmented, funicle 4-segmented; tarsi 3-segmented

Kikiki Huber and Beardsley

- $\quad$ Clava entire; funicle 5-segmented, tarsi 4-segmented

Tinkerbella Huber and Noyes 


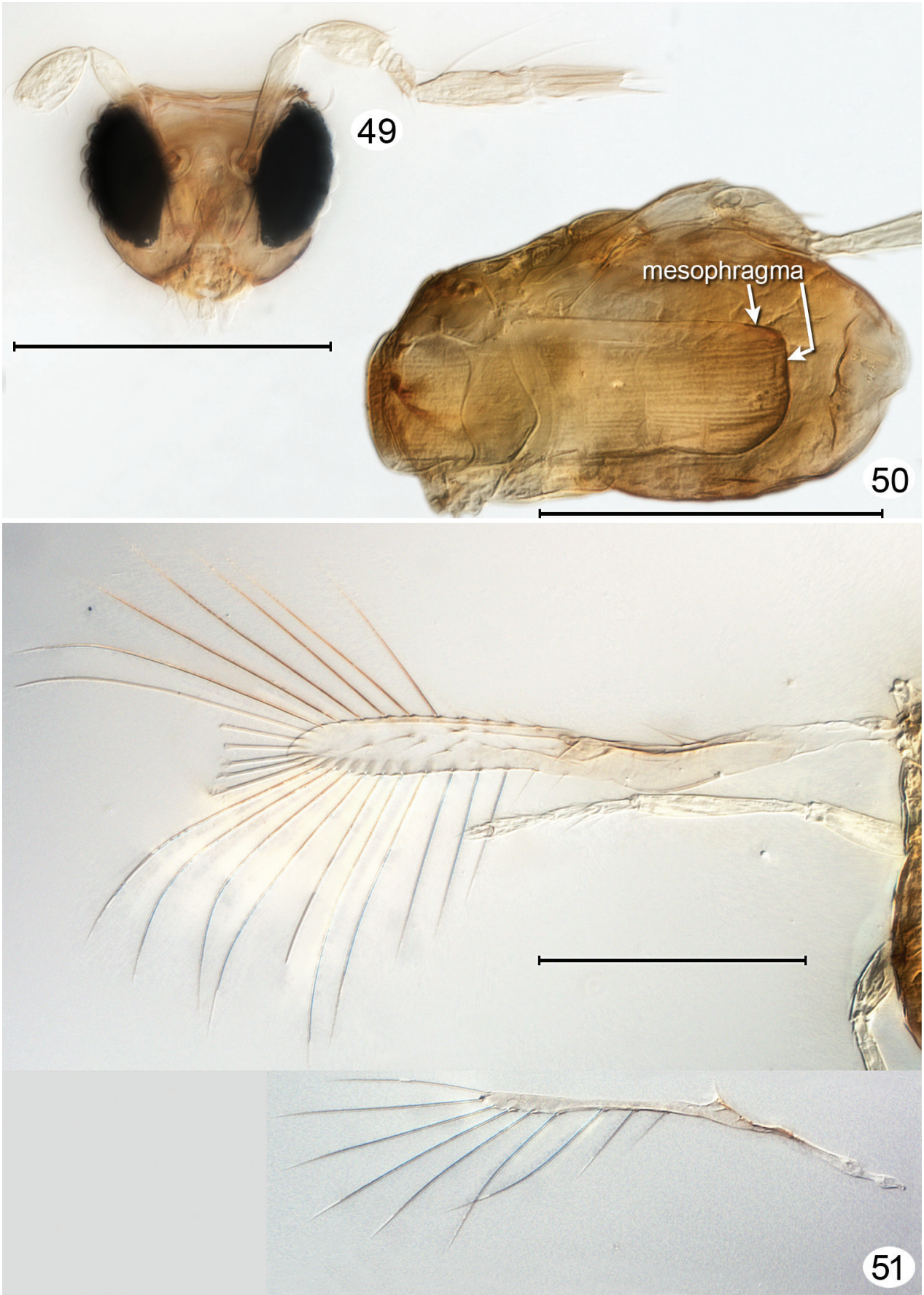

Figures 49-5 I. Megaphragma sp., uncleared on slide. 49 head + antenna, anterior (note black eyes) $\mathbf{5 0}$ mesosoma + metasoma, dorsal (note huge mesophragma, hence the genus name) $\mathbf{5} \mathbf{I}$ wings + middle leg (note 3-segmented tarsi, diagnostic for Trichogrammatidae). Scale line $=100 \mu \mathrm{m}$. 
However, several features of both genera show that their placement in the Alaptus group of genera is wrong and that they are best placed in the Anagrus-group because they share at least seven features with some or all of those genera: frenum apparently longitudinally divided by a groove, petiole and base of gaster distinctly narrower than propodeum and middle of gaster, tarsi with at most 4 tarsomeres (3 in Kikiki), stemmaticum present, mandibles with 4 teeth, fore wing venation with proximal macrochaeta much shorter than distal macrochaeta, and second phragma not projecting past posterior margin of propodeum.

Both Kikiki and Tinkerbella are distinguished from other Anagrus-group genera by the venation clearly longer than half the wing length and hind wing essentially without fringe setae on the anterior margin. The other genera in the group have the venation clearly less than half wing length and the hind wing fringed with fairly long setae on the anterior margin. No member of the Anagrus group of genera is anywhere near as small as Tinkerbella or Kikiki so these genera can be distinguished on body size alone.

Some members of the Alaptus or Camptoptera groups of genera are also extremely small but except for $A$. borinquensis none has been found that equal minute size of Tinkerbella or Kikiki, i.e., less that about $250 \mu \mathrm{m}$. One specimen of Alaptus from the same collecting event in Costa Rica as K. huna measured $272 \mu \mathrm{m}$ and species of Eofoersteria (also with 4-segmented tarsi, despite being in the Camptoptera group) are about $320 \mu \mathrm{m}$. The six specimens ( 4 females, 2 males, on 4 slides, USNM) of A. borinquensis are uncleared and mounted mostly in lateral view in Canada balsam, and some are slightly shrivelled. The smallest specimen, a male, measured $203 \mu \mathrm{m}$ in length, not $186 \mu \mathrm{m}$ as reported by Dozier (1932). The ranges for females and males, respectively, are $215-411 \mu \mathrm{m}(\mathrm{n}=4)$ and $203-311 \mu \mathrm{m}(\mathrm{n}=2)$, measured with a filar micrometer at $400 \times$ by JTH.

\section{Body size limits in arthropods}

What is the smallest size that an adult insect can attain, as measured by body length, and/or fore wing length for flying insects? If something is physically possible in living things some individuals of at least one species, extinct or extant, will likely have achieved it. So the lower size limit, by whatever measure of size is chosen, was almost certainly already evolved - somewhere, sometime. If we have not already found them, we must surely be close to discovering the smallest insects and other arthropods.

The minimum size possible for invertebrates with articulated appendages of locomotion (superphylum Arthropoda) that would allow crawling, walking, or active flight (wing flapping, not gliding) is determined by two types of constraint: internal (physiological and structural) and external (physical). For multicellular animals, the size and structure of cells cannot go below a certain minimum before they cannot function for the purpose intended. Therefore, once any type of cell has attained its minimum size, the number of cells making up a particular tissue or organ must decrease as the animal becomes smaller. But there evidently is a lower limit to cell number in any particular 
organ for it to function as intended, perhaps as low as one, e.g., a single muscle fiber or ommatidium. Or the tissue or organ may be dispensed with entirely, usually because it is no longer necessary, e.g., eye loss in obligate cave-dwelling species (troglobites). Once these internal constraints are reached the arthropod cannot become any smaller. Nuzzaci and Alberti (1996) showed that Eriophyidae (Acari) have no respiratory system and no striated muscle [in contrast to insects and other Acari, which have striated muscle exclusively (Beinbrech 1998, Alberti and Coons 1999)]. Polilov (2007) discussed miniaturization related features in Mymaridae, and Polilov (2012) showed that neurons of Megaphragma mymaripenne Timberlake are anucleate. Fischer et al. (2011) discussed size limits in ommatidia in a small parasitic wasp, Trichogramma evanescens Westwood. Grebennikov (2008) reviewed the limiting factors for small size in arthropods.

As body size decreases, external constraints, e.g., desiccation (Neville 1998), surface tension, and fluid viscosity become relatively more important. Thus, in minute organisms the muscle strength needed to power an articulated appendage for active locomotion is determined not only by internal factors such as the minimum muscle cell size and cell number but also by external factors such as viscosity of the fluid (air or water) in which active movement occurs. Although surface area to volume ratio increases with decreasing size allowing small organisms to be relatively stronger than larger organisms, there still comes a point at which muscles are so small that they cannot power an articulated appendage in a medium that, for their size, must be quite viscous. Yet, external physical factors such as air viscosity are likely still not a constraining factor because even the smallest walking or flying insects appear to be large enough to overcome them. Their problem is to overcome their own inertia, not viscosity of the fluid in which they move. For even smaller organisms than arthropods, viscosity and surface tension may finally become the limiting factor. These organisms do not (and cannot) have articulated appendages of locomotion, particularly if the appendages have intrinsic muscles that move the various segments independently.

Even with the increased mechanical efficiency resulting from smaller body size and energy conservation efficiencies conferred by Weis-Fogh clap-and-fling flapping (Weis-Fogh 1973, Miller and Peskin 2005), the elastomeric protein resilin (Neville 1998, Elvin et al. 2005), the natural elasticity of muscle and cuticle itself, and light cuticular wings (Neville 1998) it is difficult to believe for winged insects that such a small size as occurs in Kikiki huna is possible. The fact that some specimens of Megaphragma are about the same minimum size as some specimens of Kikiki suggests that winged insects have indeed reached their limit for size reduction.

A diversity of other very small insects capable of active flight have the wing surface (membrane) reduced and wing fringes, especially of the hind wing, greatly lengthened, e.g., species of Thysanoptera, various families of small Lepidoptera and parasitic Hymenoptera, and Ptiliidae (Coleoptera). While this may slightly reduce wing weight the reduced wing surface and relatively long setae are more likely to have an aerodynamic function, perhaps to reduce turbulence and hence drag on a wing flapping at several hundred beats per second. Interestingly, in Kikiki (Fig. 27), Tinkerbella (Fig. 6) and Megaphragma (Fig. 51) the fringe setae along the leading edge of the hind wing are 
absent or almost so, whereas in other genera of Trichogrammatidae and Mymaridae they are present, albeit short. The separation of muscles that power flapping, i.e., the indirect flight muscles that cause thoracic distortion, resulting in wing flapping, from the direct flight muscles that control wing pitch may also be important in allowing insects capable of active flight to attain a minute body size.

Relatively long legs powered by sufficiently strong muscles to elevate the body may be linked to and necessary for active flight. The muscles required to move articulated legs to enable walking by lifting the entire body off the ground and moving forward must have a lower size limit or the legs could not be used for that purpose. Two sets of opposing intrinsic muscles are needed: extensor/elevator muscles strong enough to lift the entire body sufficiently above the substrate to initiate flight, perhaps by allowing a wing stroke of more than $90^{\circ}$, and flexor/depressor muscles to allow walking, and perhaps secondarily to draw the legs against the body during flight to reduce drag. High speed photography of Trichogramma lifting off a substrate (Lentink and Voesenek 2012) suggests that the first wing stroke is greater than $90^{\circ}$ and, once airborne, that individuals in flight move forward by pushing air forcefully backwards, especially on the up stroke. With about 350 wing beats per second Trichogramma individuals keep themselves in a reasonably high Reynolds number range. But the video clip does not seem to show that the legs are used to leap vertically off the substrate prior to initiating a wing flap. In these wasps the legs need only be long and strong enough to lift the entire body off the ground for normal walking and perhaps to allow the first wing flap to be greater than $90^{\circ}$, sufficient to allow lift off. Trichogramma spp, have relatively wide wings, $(200-300 \mu \mathrm{m})$, with a fore wing width to length ratio about 0.5 and wing fringes that are about $0.2 \times$ wing width. These are quite unlike Kikiki, with a forewing width of $20-25 \mu \mathrm{m}$, a width to length ratio of 0.11 and fringes about $5.0 \times$ the wing width, so flight aerodynamics between the two genera may be very different.

In insects with free living adults and larvae the lower body length limit seems to be about $400 \mu \mathrm{m}$ (Grebennikov 2008), imposed by the need to have a sufficiently large egg to nourish the developing larva sufficiently so it can be free-living, i.e., it must have the necessary initial body resources to move around actively upon hatching, perhaps to search for food and avoid potential predators. Females of the smallest oribatid mites (Acari) also lay only a single, relatively enormous egg at a time, e.g., a species of Brachychthonius (Brachychthoniidae) with a female $180 \mu \mathrm{m}$ long (distorted by compression of the coverslip) has an egg of $100 \mu \mathrm{m}$ (D. Walter, pers. comm.). The smallest known fly is also $0.4 \mathrm{~mm}$ long (Brown 2012).

The constraint of minimum egg size as a determinant of minimum body size does not apply to parasitic insects. Eggs in these can be much smaller because the larvae hatch inside the host. They do not have to search actively for food because it completely envelops them. The limiting factor to small size in adult parasitic insects must therefore be minimum cell size and sufficient cells of each type of tissue, as discussed above. Females of Tinkerbella, Kikiki, and A. borinquensis are the smallest Mymaridae, and some specimens of Kikiki are the smallest recorded winged insects. The body length of five specimens from Costa Rica is $158 \mu \mathrm{m}$ ( 1 female), $160 \mu \mathrm{m}$ ( 2 females), and 170 
$\mu \mathrm{m}$ (2 females). Three specimens are thus smaller than the smallest recorded females of Megaphragma caribea, the previous record holder at $170 \mu \mathrm{m}$ (Delvare 1993).

The next step in body length reduction in insects is in D. echmepterygis. Females are winged and relatively long (one measured $386 \mu \mathrm{m}$ dry but not shivelled and $550 \mu \mathrm{m}$ on a slide mount), but the males slide-mounted males were 139-240 $\mu \mathrm{m}$ long $(\mathrm{n}=8)$ (Mockford 1997). One critical point dried female (CNC) measured by JTH is 340 $\mu \mathrm{m}$ long and two critical point dried males (BMNH, CNC) from the remaining 10 male paratypes, measured independently by JTH and JSN are $126.17 \mu \mathrm{m}$ and $130 \mu \mathrm{m}$, respectively (ESEM measurement). Males have significant morphological reductions or losses. They lack eyes and ocelli, and the appendages are greatly reduced (antenna, tarsi) or absent (wings, mouthparts) (Figs 52-55). Because they cannot feed their only energy source is what has been stored as larvae, which would have obtained all their nutrients from their psocopteran host egg. The leg segments of males are strangely disproportionate, with huge coxae (Figs 52, 53, 55) as long as the femora, protibiae shorter than the femora, and the tarsi absent except for the large, bell-shaped arolium on each (Figs 52, 55) that presumably acts as suction cups to attach to females. Because the legs, especially the hind legs, are long relative to the body length, males clearly can raise their entire body above the substrate in order to walk more or less normally over the short distance necessary to find a female. The tarsal structure, and the fact that some males were found attached to females (Mockford 1997), show that males are phoretic and need only walk only far enough to crawl onto a female to copulate, almost certainly while the female is still in the egg (females presumably emerge from the same host egg or egg cluster so the distance traversed by a male is very short). Males evidently have enough energy to do this and probably nothing else.

Further reductions in body length occur in terrestrial Arthropoda other than insects. In mites, the smallest adult individuals of several species in three families are less than $95 \mu \mathrm{m}$ in length: Cochlodispus minimus Mahunka at $79 \mu \mathrm{m}$ (Mahunka 1976) and Microdispus australis Mahunka at $82 \mu \mathrm{m}$ (Mahunka 1969) (both Microdispidae), female of Indosetacus rhinacanthi Ghosh and Chakrabarti at $86 \mu \mathrm{m}$ (Ghosh and Chakrabarti 1987), male of Eriophyes parvulus (Nalepa) at $90 \mu \mathrm{m}$ (Nalepa 1892), both sexes of Achaetocoptes quercifolii Farkas at $90 \mu \mathrm{m}$ (Farkas 1961) (all Eriophyidae), and females of Iponemus truncatus eurus Lindquist at $93 \mu \mathrm{m}$ and I. confusus oriens (Lindquist and Bedard) at $94 \mu \mathrm{m}$ (both Tarsonemidae) (Lindquist 1969). That small size in arthropods is not a recent evolutionary phenomenon is shown by a Triassic mite, Ampezzoa triassica Lindquist and Grimaldi (Eriophyidae), $124 \mu \mathrm{m}$ in length (Schmidt et al. 2012). Adults of Eriophyidae have only two pairs of usually 5-segmented legs yet they are evidently capable of locomotion but the legs are so reduced that they cannot lift the entire body off the substrate. "Walking" in Eriophyidae is an inching or looping motion. The more or less worm-like body is arched between the two pairs of forelegs anteriorly and the terminal sucker posteriorly, and alternate gripping and releasing by the legs and sucker allow the mite to inch along. True walking using the legs only presumably does not occur and they probably do not move much by this method during their life time. Instead, dispersal is by aerial drifting. However, Microdispidae and Tarsonemidae have 4 pairs 


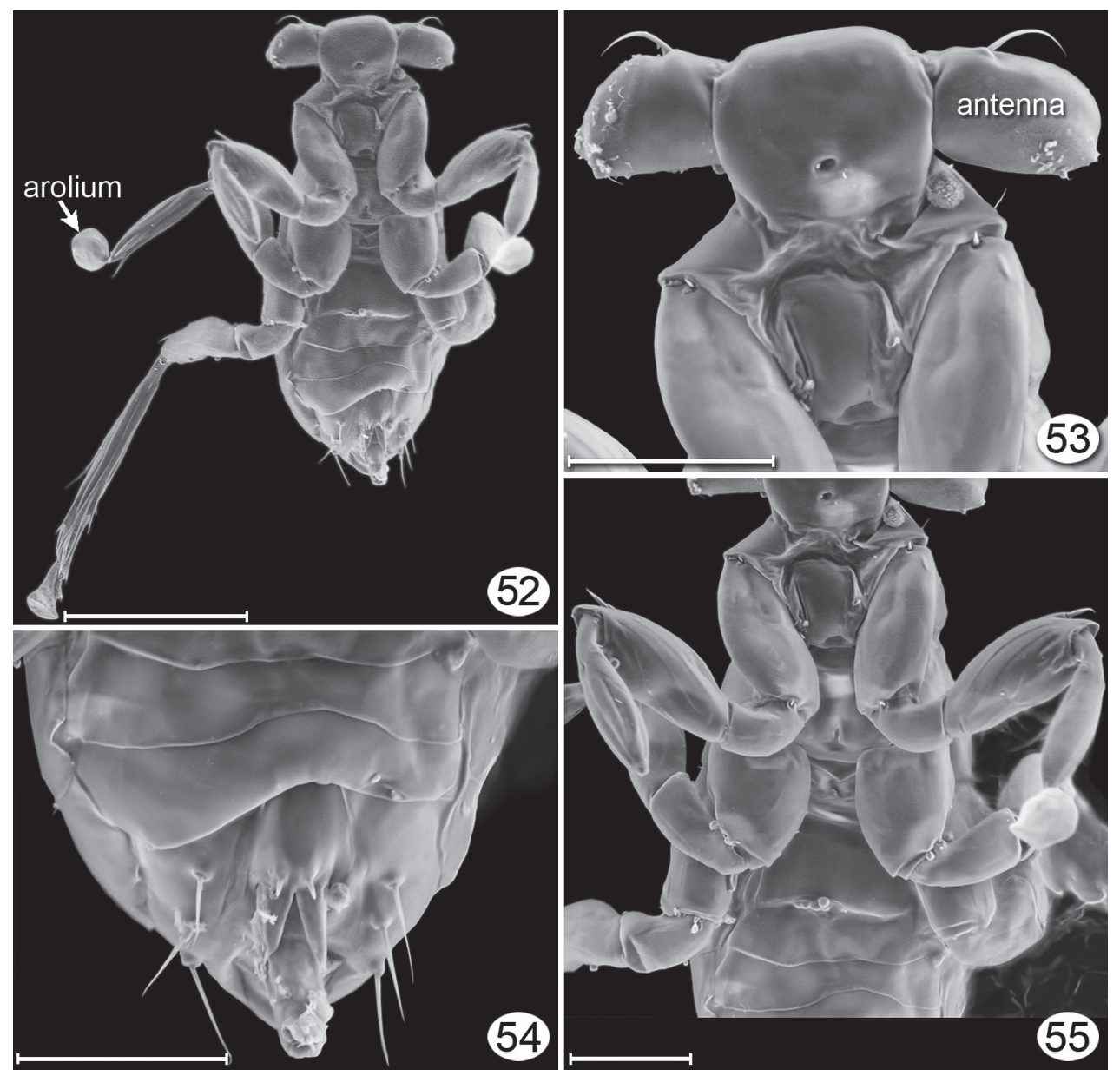

Figures 52-55. Dicopomorpha echmepterygis male, paratype, ventral. $\mathbf{5 2}$ habitus $\mathbf{5 3}$ head + prothorax + procoxa $\mathbf{5 4}$ apex of gaster $\mathbf{5 5}$ mesosoma + base of most legs and metasoma. Scale line $=20 \mu \mathrm{m}$, except Fig. $52=50 \mu \mathrm{m}$.

of legs and are capable of normal walking. The smallest adult of Neoliochthonius piluliferus (Forsslund) (Brachychthoniidae) is $123 \mu \mathrm{m}$ (Forsslund 1942). If a mite doubles in size with each moult or increases in body length by a factor of about 1.3 (Hutchinson's Ratio-applied to comparison of different life stages within a species instead of comparing competing species in the same habitat) a larva or protonymph would be as small as about $50 \mu \mathrm{m}$ in length. A larva of this length was found by D. Walter (pers. comm.). Whereas Insecta have two sets of opposing intrinsic muscles in their leg segments (Fig. 47) as indicated above, Acari only have flexors (except for those moving the apotele, at the apex of the tarsus). In all Acari the distal segments flex due to muscular contraction and extend due to hydrostatic pressure (Alberti and Coons 1999).

For comparison with terrestrial arthropods, larvae of the marine parasites of Copepoda Stygotantulus stocki Boxhall and Huys at $94 \mu \mathrm{m}$ (Boxhall and Huys 1989) and Tan- 
tulus dieteri Mohrbeck, Arbizu and Glatzel (Crustacea: Tantulocarida, Basipodellidae) (Mohrbeck et al. 2010, Martin and Davis 2001) at ca. $85 \mu \mathrm{m}$ are the shortest. Notably, all members of the subclass lack recognizable cephalic limbs, other than paired antennules in one known stage (Martin and Davis 2001). The loss of appendages and the parasitic life style of adults means that the much higher viscosity of water compared to air is irrelevant in impeding locomotion, because the immature stages evidently disperse by passive drifting (as do Eriophyidae), and adults are parasitic so evidently do not move.

Below a certain body length it is useless to have articulated appendages because the segments could not be moved relative to one another, or the entire appendage relative to the body, by intrinsic muscle power alone. Instead, if appendages of locomotion exist at all (e.g., pseudopods), they would be short and wide, would not be articulated, and would be moved instead by body muscles causing hydrostatic changes in pressure, combined perhaps with flexor muscles originating within the body but attached near or at the appendage apex. The length of the larva of $N$. piluliferus rivals some Rotifera, also as short as $50 \mu \mathrm{m}$, suggesting that at about this size the changeover from locomotion by partial muscle power intrinsic to leg segments (Acari) to hydrostatic power alone (Rotifera, other non-Arthropoda) may occur.

We suggest that the smallest winged insects capable of flapping flight could not be less than about $150 \mu \mathrm{m}$ in length, and the smallest capable of normal walking (body lifted entirely of substrate) not below about $125 \mu \mathrm{m}$. Among insects, Kikiki huna may well have attained the lower limit for active flight and Dicopomorpha echmepterygis the lower limit for normal walking. Among other arthropods capable of walking, $80 \mu \mathrm{m}$ is suggested as the lower limit for adults and ca. $50 \mu \mathrm{m}$ for immatures.

\section{Acknowledgements}

We thank J. Read (Natural Resources Canada, Ottawa) for preparing the photographs and micrographs and compiling the plates, the senior author's brother, P. Huber (Hanover, New Hampshire), for discussions on the effect of air viscosity for very small flying insects, E. Lindquist (Agriculture and Agri-Food Canada, Ottawa) and D. Walter (Royal Alberta Museum, Edmonton) for interesting discussions and information on Acari, and V. Grebennikov (Canadian Food Inspection Agency, Ottawa) for information on publications by A. Polilov. The type series of $A$. borinquensis was sent to JTH by M. Gates (Systematic Entomology Laboratory, National Museum of Natural History, Washington, DC) and we are grateful for his help.

\section{References}

Alberti G, Coons LB (1999) Chapter 6. Acari: Mites. In: Harrison FW, Foelix RF (Eds) Microscopic Anatomy of Invertebrates. Volume 8C. Chelicerate Arthropoda. Wiley-Liss, New York, 515-1215. 
Beardsley JW, Huber JT (2000) Key to genera of Mymaridae from the Hawaiian Islands, with notes on some of the species (Hymenoptera: Mymaridae). Proceedings of the Hawaiian Entomological Society 34: 1-22.

Beinbrech G (1998) Chapter 23. Muscle Structure. In: Harrison FW, Locke M (Eds) Microscopic Anatomy of Invertebrates. Volume 11B. Insecta. Wiley-Liss, New York, 553-572.

Boxhall GA, Huys R (1989) New tantulocarid, Stygotantulus stocki, parasitic on harpacticoid copepods, with an analysis of the phylogenetic relationships within the Maxillopoda. Journal of Crustacean Biology 9: 126-140. doi: 10.2307/1548454

Brown BV (2012) Small size no protection for acrobat ants: world's smallest fly is a parasitic phorid (Diptera: Phoridae). Annals of the Entomological Society of America 105: 550-554. doi: 10.1603/AN12011

Delvare G (1993) Sur les Megaphragma de Guadeloupe avec la description d'une espèce nouvelle [Hymenoptera, Trichogrammatidae]. Revue française d'Entomologie (Nouvelle Série) 15: 149-152.

Dozier HL (1932) Descriptions of mymarid egg parasites from Haiti and Puerto Rico. Journal of the Department of Agriculture of Puerto Rico 16: 81-91.

Elvin CM, Carr AG, Huson MG, Maxwell JM, Pearson RD, Vuocolo T, Liyou NE, Wang DCC, Merritt DJ, Dixon NE (2005) Synthesis and properties of crosslinked recombinant pro-resilin. Nature 437: 999-1002. doi: 10.1038/nature04085

Enock F (1895) An aquatic hymenopterous insect. Science Gossip 2: 89.

Farkas HK (1961) Über die Eriophyiden (Acarina) Ungarns II. Beschreibung neuer Gattung und zwei neuer Arten. Acta Zoologica Academiae Scientiarum Hungaricae 7: 73-76.

Fischer S, Müller CHG, Meyer-Rochow B (2011) How small can small be: the compound eye of the parasitoid wasp Trichogramma evanescens (Westwood, 1833) (Hymenoptera, Hexapoda), an insect of 0.3- to 0.4-mm total body size. Visual Neuroscience 28: 295-308. doi: $10.1017 / S 0952523810000192$

Forsslund KH (1942) Schwedische Oribatei (Acari) I. Arkiv för Zoologi 34A(10): 1-11.

Ghosh NK, Chakrabarti S (1987) A new genus and three new species of eriophyid mites (Acarina: Eriophyoidea) from West Bengal India. Entomon 12: 49-54.

Gibson GAP (1997) Chapter 2. Morphology and terminology. In: Gibson GAP, Huber JT, Woolley JB (Eds) Annotated keys to the genera of Nearctic Chalcidoidea (Hymenoptera). NRC Research Press, Ottawa, 16-44.

Grebennikov VV (2008) How small can you go: factors limiting body miniaturization in winged insects with a review of the panatropical genus Discheramocephalus and description of six new species of the smallest beetles (Pterygota: Coleoptera: Ptiliidae). European Journal of Entomology 105: 313-328.

Huber J, Landry J-F (2000) Cutio nanissimus incredibilis. Nouv'Ailes 9(3): 11. [In French] Huber JT (2009a) Biodiversity of Hymenoptera. In: Foottit RG, Adler PH (Eds) Insect Biodiversity: Science and Society. Blackwell Publishing, London, 303-323. doi: 10.1002/9781444308211.ch12

Huber JT (2009b) The genus Dicopomorpha (Hymenoptera, Mymaridae) in Africa and a key to Alaptus-group genera. Zookeys 20: 233-244. doi: 10.3897/zookeys.20.116 
Huber JT (2012) Revision of Ooctonus (Hymenoptera: Mymaridae) in the Nearctic region. Journal of the Entomological Society of Ontario 143: 15-105.

Huber JT, Beardsley JW (2000a) Key to Gonatocerus from the Hawaiian Islands, with notes on the species (Hymenoptera: Mymaridae). Proceedings of the Hawaiian Entomological Society 34: 49-60.

Huber JT, Beardsley JW (2000b) A new genus of fairyfly, Kikiki, from the Hawaiian Islands (Hymenoptera: Mymaridae). Proceedings of the Hawaiian Entomological Society 34: 65-70.

Huber JT, Lin N-Q (1999) World review of the Camptoptera group of genera (Hymenoptera: Mymaridae). Proceedings of the Entomological Society of Ontario 130: 21-65.

Lentink D, Voesenek K (2012) Trichogramma flight video. A second in the life of a parasitic wasp. Wageningen University, Wageningen.

Lin N-Q, Huber JT, La Salle J (2007) The Australian genera of Mymaridae (Hymenoptera: Chalcidoidea). Zootaxa 1596: 1-111.

Lindquist EE (1969) Review of Holarctic tarsonemid mites (Acarina: Prostigmata) parasitizing eggs of ipine bark beetles. Memoirs of the Entomological Society of Canada 60: 1-111. doi: $10.4039 /$ entm $10160 \mathrm{fv}$

Luft Albarracin EL, Triapitsyn SV, Virla EG (2009) Annotated key to the genera of Mymaridae (Hymenoptera: Chalcidoidea) of Argentina. Zootaxa 2129: 1-28.

Mahunka S (1969) The scientific results of the Hungarian soil zoological expeditions to South America 9. Acari: Pyemotidae and Scutacaridae from the Guayaramerin Region in Bolivia. Acta Zoologica Academiae Scientiarum Hungaricae 15: 63-90.

Mahunka S (1976) Äethiopische Tarsonemiden (Acari: Tarsonemida). II. Acta Zoologica Academiae Scientiarum Hungaricae 22: 69-96.

Martin JW, Davis GE (2001) An updated classification of the recent Crustacea. Natural History Museum of Los Angeles County, Science Series 39: 1-124.

Miller LA, Peskin CS (2005) A computational fluid dynamics of 'clap and fling' in the smallest insects. Journal of Experimental Biology 208: 195-212. doi: 10.1242/jeb.01376

Mockford EL (1997) A new species of Dicopomorpha (Hymenoptera: Mymaridae) with diminutive, apterous males. Annals of the Entomological Society of America 90: 115-120.

Mohrbeck I, Martínez P, Glazel T (2010) Tantulocarida (Crustacea) from the Southern Ocean deep sea, and the description of three new species of Tantulacus Huys, Andersen \& Kristensen, 1992. Systematic Parasitology 77: 131-151. doi: 10.1007/s11230-010-9260-0

Nalepa A (1892) Neue Arten der Gattung Phytoptus Duj. und Cecidophys Nal. Denkschriften der kaiserlichen Akademie der Wissenschaften Mathematich-naturwissenschaftliche Klasse 59: $525-540+4$ plates.

Neville C (1998) Chapter 7. The significance of insect cuticle. In: Harrison FW, Locke M (Eds) Microscopic Anatomy of Invertebrates. Volume 11A. Insecta. Wiley-Liss, New York, 151-176.

Nuzzaci G, Alberti G (1996) Chapter 1.2. Internal anatomy and physiology. In: Lindquist EE, Sabelis MW, Bruin J (Eds) Eriophyoid mites: their biology, natural enemies and control. Elsevier Science, Amsterdam, 101-150. doi: 10.1016/S1572-4379(96)80006-6

Polilov AA (2007) Miniaturization-related structural features in Mymaridae. In: Rasnitsyn AP, Gokhman VE (Eds) Studies on Hymenopteran Insects. KMK Scientific Press, Moscow, 50-64. 
Polilov AA (2012) The smallest insects evolve anucleate neurons. Arthropod Structure \& Development 41: 29-34.

Schmidt AR, Jancke S, Lindquist E, Ragazzi E, Roghi G, Nascimbene PC, Schmidt K, Wappler T, Grimaldi DA (2012) Arthropods in amber from the Triassic Period. doi: 10.1073/ pnas. 1208464109

Triapitsyn SV, Beardsley JW (2000) A review of the Hawaiian species of Anagrus (Hymenoptera: Mymaridae). Proceedings of the Hawaiian Entomological Society 34: 23-48.

Weis-Fogh T (1973) Quick estimation of flight fitness in hovering animals, including novel mechanism for lift production. Journal of Experimental Biology 59: 169-230.

\section{Appendix}

Abbreviations used in the figures: as = anterior scutellum, ax $=$ axilla, $\mathrm{dm}=$ distal macrochaeta, dor $=$ dorsellum, $\mathrm{fl}=$ funicle segment, $\mathrm{fr}=$ frenum, $\mathrm{mlm}=$ mid lobe of mesoscutum, $\mathrm{mps}=$ multiporous plate sensillum, $\mathrm{pd}=$ propodeum, $\mathrm{pm}=$ proximal macrochaeta, $\mathrm{sp}=$ spiracle . 